\title{
Effect of Water Submergence on the Characteristics of Bituminous Mixes Using Reclaimed Asphalt Pavement
}

\author{
Md. Akhtar Hossain, Md. Harun Ar Rashid", Md. Mamunur Rashid \\ Department of Civil Engineering, Rajshahi University of Engineering \& Technology, Rajshahi, Bangladesh \\ Email address: \\ akhtar412002@yahoo.com (Md. A. Hossain), harashid074@gmail.com (Md. H. Ar Rashid), mamunrashid.ruet@gmail.com (Md. M. Rashid) \\ ${ }^{*}$ Corresponding author
}

\section{To cite this article:}

Md. Akhtar Hossain, Md. Harun Ar Rashid, Md. Mamunur Rashid. Effect of Water Submergence on the Characteristics of Bituminous Mixes Using Reclaimed Asphalt Pavement. European Journal of Biophysics. Vol. 6, No. 1, 2018, pp. 1-6. doi: 10.11648/j.ejb.20180601.11

Received: December 18, 2017; Accepted: January 4, 2018; Published: January 19, 2018

\begin{abstract}
Now a-days, the cost of asphalt pavement materials have been increasing excessively, which led to find alternative materials which must be cheaper than that of asphalt pavement materials. In addition, more concerns are pointed to reserving natural resources and reducing environmental impacts of using virgin asphalt binders, thus more attention is focused on the use of recycled materials in pavement designs. The main purpose of this study is to investigate the effect of water on the use of reclaimed asphalt pavement materials in bituminous mix and to determine the optimum percentage of reclaimed asphalt pavement materials with virgin pavement materials and optimum days of water submergence according to the Marshall Mix design criteria based on medium traffic condition. To achieve the objectives of this study the basic properties tests were performed on the studied materials and then Marshall Test was conducted on asphalt mixtures with different percentages of reclaimed asphalt pavement materials with optimum bitumen content determined for $100 \%$ fresh aggregate. The different percentages of reclaimed asphalt pavement material in asphalt mixtures are $0 \%, 10 \%, 20 \%, 30 \%$ and $40 \%$. Marshall Criteria was satisfied up to $20 \%$. Then the specimen prepared with $20 \%$ reclaimed asphalt pavement material was submerged in water at $0,5,10,15$ and 20 days. Optimum days of water submergence was 15 days on the basis of Marshall mix design criteria.
\end{abstract}

Keywords: Reclaimed Asphalt Pavement, Gradation, Optimum Bitumen Content, Marshall Stability, Water Effect

\section{Introduction}

Reclaimed asphalt pavement (RAP) creates a mean for reusing materials that optimizes the use of natural resources. RAP is an economical alternative to virgin materials because it reduces the need to use virgin aggregate, which is a scare material many parts of Bangladesh. It also reduces the amount of binder required in the production of asphalt paving mixtures. Using RAP is environmentally friendly. It helps to conserve natural resources and reduce the amount of land for the disposal of these materials.

Hot mix recycling is the process in which reclaimed asphalt pavement materials are combined with new materials, sometimes along with a recycling agent, to produce hot mix asphalt (HMA) mixture The two steps in the mix design procedure are material evaluation and mix design.

The objective for the design of bituminous mix is to determine a logical and economical blend and gradation of aggregates with the corresponding bitumen content. The two fundamental properties of bituminous paving mixture which are held to be of utmost importance are stability and durability. In addition to stability and durability, a well-designed mixture must satisfy traffic safety requirement. Above all, the mix must also be economical as possible.

In recent years, a lot of research work has been done to make use of reclaimed asphalt pavement materials into the bituminous mix to make it cost effective.

Hussain et al. (2012) represented on "Laboratory evaluation of asphalt mixtures containing various percentages of reclaimed asphalt pavement" that mixtures containing RAP shows significant variability and the variability increases with the increase in RAP content. Four mixtures, which are the combination of two different virgin aggregates and two different RAP sources, are studied in this research.

Pradyumna et al. (2013) examined on "Characterization of Reclaimed Asphalt Pavement (RAP) for using in bituminous road construction" that the addition of RAP improves all the 
properties of the bituminous mixes. This indicates that mixes with $20 \%$ RAP would perform better than the virgin mixes under similar condition. The bituminous rejuvenating agent which was prepared in the laboratory was added to the recover binder obtained from the RAP material in various dosages of $10 \%, 15 \%$ and $20 \%$.

Udayshankar et al. (2013) found that "Laboratory studies of dense bituminous mixes-II with reclaimed pavement materials" that the mixtures containing RAP showed significant variability and the variability increased with the increase in RAP content. The mixtures were designed by Marshall method as per Asphalt institute (MS-II) at 20\% and $30 \%$ RAP. The total is reduced around $20 \%-30 \%$ comparing with the virgin mixes.

Srikant et al. (2014) determined that "Comparative evaluation of warm mix asphalt containing reclaimed asphalt pavement for DBM II mix" that the test results indicate improvement in laboratory performance, encouraging the use of reclaimed asphalt pavement materials in warm mix asphalt mixes. Warm mix prepared at $1200^{\circ} \mathrm{C}$ mixing with $30 \%$ RAP content shows higher stability when compared with warm mix prepared at $110^{\circ} \mathrm{C}$.

Mohamady et al. (2014) examined on "Effect of using Reclaimed Asphalt Pavement on asphalt mix performance" that the percent of RAP maybe $30 \%$ to ensure superior field performance after construction. Asphalt concrete specimens are prepared at optimum asphalt content resulted in Marshall test to be investigated through indirect tensile strength test and loss of stability test. The six asphalt mixtures contain different percentages of RAP (i.e. $0 \%, 10 \%, 20 \%, 30 \%, 40 \%$ and $50 \%$ ).

Sunil et al. (2014) represented on "Experimental investigations on the performance of bituminous mixes with reclaimed asphalt pavement (RAP) materials (case study Tumkur to Chitradurga- $\mathrm{NH}_{4}$ )" that RAP mixes shows good Marshall stability, indirect tensile strength and fatigue life similar to conventional asphalt mix. Bituminous mixes prepared with $10 \%, 20 \%, 30 \%$ and $40 \%$ RAP material obtained by scarifying distressed asphalt pavement, surface new aggregate and bitumen such as VG-30 without using any rejuvenator. The study shows that about $20 \%$ and $30 \%$ of the cost of the wearing courses or binder courses can be effectively reduced with all the other liabilities.

Elmohr et al. (2015) examined on "Characterization of reclaimed asphalt pavement (RAP) for using flexible pavement" that the bituminous mixes with RAP especially at $50 \%$ to $100 \%$ replacement ratio provide better performance compared to those of new conventional HMA mixtures where they minimize the environmental impacts through the reduction of energy consumption, improves the mechanical properties, durability performance and also stripping resistance. The addition of RAP has a great influence on improving the indirect tensile strength where the highest values are achieved at 50\% RAP content.

\section{Methodology}

The study was based on materials collection, materials properties, experimental program and compare the values with Marshall Mix design criteria based on medium traffic condition.

\subsection{Materials Collection}

Black stone chips to the size of $25 \mathrm{~mm}$ and less was used in this investigation as fresh coarse aggregate. The source of the black stone chips is Pakur, India. RAP material is collected from Natore. Combination of Domar sand and Padma river sand was the main source of fine aggregate and mineral filler. The bitumen was of $80-100$ penetration grade bitumen collected from eastern refinery, Chittagong.

\subsection{Material Properties}

Material properties were determined according to the test procedures specified by AASHTO and BS standards.

Table 1. Properties of Mineral Aggregates.

\begin{tabular}{llllll}
\hline Properties & Method (AASHTO) & Coarse Aggregate (Fresh) & Coarse Aggregate (RAP) & Fine Aggregate & Mineral Filler \\
\hline Unit weight, $\mathrm{kg} / \mathrm{m}^{3}$ & T19 & 1528 & 1524 & 1430 & 1150 \\
Specific gravity & T85 & 2.76 & 2.72 & 2.46 & \\
Water absorption, (\%) & T85 & 75 & 72 & \\
L. A. A., (\%) & T96 & 19 & 22 & \\
AIV, (\%) & BS812 & 7 & 9 & \\
ACV, (\%) & BS812 & 17 & 20 & \\
\hline
\end{tabular}

Table 2. Properties of Bitumen.

\begin{tabular}{|c|c|c|}
\hline Properties & Method (AASHTO) & Test Value \\
\hline Specific gravity (at $\left.25^{\circ} \mathrm{C}\right)$ & T229 & 1.01 \\
\hline Penetration (at $25^{\circ} \mathrm{C}, 100 \mathrm{gm}$ and 5 seconds) & $\mathrm{T} 49$ & 83 \\
\hline Loss on heating (at $163^{\circ} \mathrm{C}, 5$ hours), $(\%)$ & $\mathrm{T} 47$ & 0.42 \\
\hline Ductility $\left(\right.$ at $\left.25^{\circ} \mathrm{C}\right), \mathrm{cm}$ & $\mathrm{T} 51$ & $100^{+}$ \\
\hline Solubility (by $\left.\mathrm{CCl}_{4}\right),(\%)$ & $\mathrm{T} 44$ & 99.6 \\
\hline Flash point, ${ }^{\circ} \mathrm{C}$ & $\mathrm{T} 48$ & 272 \\
\hline Fire point, ${ }^{\circ} \mathrm{C}$ & $\mathrm{T} 48$ & 280 \\
\hline
\end{tabular}




\subsection{Experimental Program}

Experimental program is divided into three steps, such as determination of optimum bitumen content, determination of optimum percentage of RAP and optimum days of water submergence.

\subsubsection{Determination of Optimum Bitumen Content}

At first optimum bitumen content was determined for $100 \%$ fresh aggregate. The test procedure introduced by Bruce
Marshall and developed by the U.S. corps of engineers has been followed in the laboratory investigations. It was observed from the trial mixes that about 1200 gms of aggregates were required to prepare one specimen of 101.6 $\mathrm{mm}$ (4 in.) diameter and $63.5 \mathrm{~mm}$ (2.5 in.) thick. Aggregate were selected according to the aggregate grading proposed by The Asphalt Institute giving in Table 3. Specific gravity of the specimen was determined according to AASHTO (1983) $\mathrm{T} 166$. Then the specimen was subjected to Marshall stability and flow test.

Table 3. Aggregate grading (The Asphalt Institute, 1974).

\begin{tabular}{lllll}
\hline Sieve $\mathbf{~ m m}$ & \% passing by weight & Individual Retain (\%) & \% of CA, FA \& $\mathbf{M F}$ & Individual weight, for 1200 gm \\
\hline 25 & 100 & 00 & & \\
19 & 90 & 10 & $\mathrm{CA}=58 \%$ & 120 \\
9.5 & 70 & 20 & & 240 \\
4.75 & 56 & 14 & & 168 \\
2.36 & 42 & 14 & & 168 \\
0.60 & 25 & 17 & $\mathrm{FA}=38 \%$ & 204 \\
0.30 & 18 & 07 & & 84 \\
0.15 & 11 & 07 & $\mathrm{MF}=4 \%$ & 84 \\
0.075 & 4 & 07 & & 84 \\
& & & 48 \\
\hline
\end{tabular}

\subsubsection{Determination of Optimum Percentage of RAP}

After determination of OBC, RAP materials mixes with fresh aggregates on $0 \%, 10 \%, 20 \%, 30 \%, 40 \%$ of total percentage of coarse aggregate. Bituminous mould was prepared of this percentage with OBC by Marshall mix design method. Specific gravity of the specimen was determined according to AASHTO (1983) T 166. Then the specimen was subjected to Marshall stability and flow test. Optimum percentage of RAP was determined according to the Marshall mix design criteria based on medium traffic condition.

Table 4. Marshall Mix Design Criteria (The Asphalt Institute, 1997).

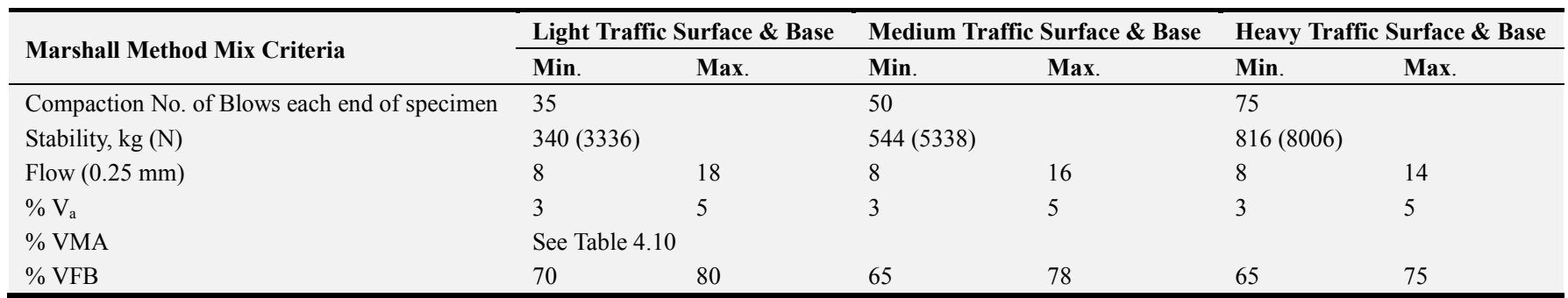

Table 5. Minimum \% VMA for the Marshall Method.

\begin{tabular}{llll}
\hline \multirow{2}{*}{ Nominal Particle Size (mm) } & \multicolumn{3}{l}{ Minimum VMA (\%) } \\
\cline { 2 - 4 } & \multicolumn{3}{l}{ Design Air Voids (\%) } \\
\cline { 2 - 4 } & $\mathbf{3 . 0}$ & $\mathbf{4 . 0}$ & $\mathbf{5 . 0}$ \\
\hline 1.08 & 21.5 & 22.5 & 23.5 \\
2.36 & 19 & 20 & 21 \\
4.75 & 16 & 17 & 18 \\
9.5 & 14 & 15 & 16 \\
12.5 & 13 & 14 & 15 \\
19.0 & 12 & 13 & 14 \\
25.0 & 11 & 12 & 13 \\
37.5 & 10 & 11 & 12 \\
50.0 & 9.5 & 10.5 & 11.5 \\
\hline
\end{tabular}

Traffic Classification:
Light: Traffic conditions resulting in a Design EAL $<10^{4}$ or C. $\mathrm{V}<150$ / day

Medium: Traffic conditions resulting in a Design EAL $=$ $10^{4}-10^{6}$ or $\mathrm{C}$. $\mathrm{V}=(150-300) /$ day. (Where $\mathrm{C}$. $\mathrm{V}=$ Commercial Vehicle)

Heavy: Traffic conditions resulting in a Design EAL $>10^{6}$

\subsubsection{Determination of Optimum Days of Water Submergence}

After that Marshall criteria satisfied economical RAP percentage was selected. Then these RAP percentage specimen was prepared and taken the specimen in water at 0 , 5, 10, 15, 20 days. After that optimum days of watering was determined according to Marshall mix design criteria based on medium traffic condition. 


\section{Results}

Table 6. Marshall test results of bituminous mixes without RAP materials.

\begin{tabular}{llllll}
\hline SL NO. & $\mathbf{1}$ & $\mathbf{2}$ & $\mathbf{3}$ & $\mathbf{4}$ & $\mathbf{5}$ \\
\hline \% BC & 4.5 & 5 & 5.5 & 6 & 6.5 \\
Unit weight $\left(\mathrm{kg} / \mathrm{m}^{3}\right)$ & 2311 & 2311 & 2349 & 2332 & 2321 \\
Marshall Stability $(\mathrm{KN})$ & 13.4 & 14 & 15.6 & 14.8 & 13.7 \\
Flow value & 13 & 13 & 14 & 15 & 16 \\
\% Va & 6.9 & 5.4 & 3.9 & 3.6 & 3.8 \\
\% VMA & 15.5 & 15.2 & 15 & 15.8 & 17 \\
\% VFB & 55.5 & 64.5 & 74 & 77.2 & 77.6 \\
\hline
\end{tabular}

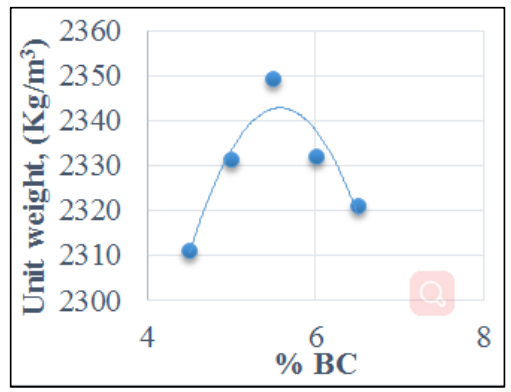

Figure 1. Relationship between unit weight and bitumen content.

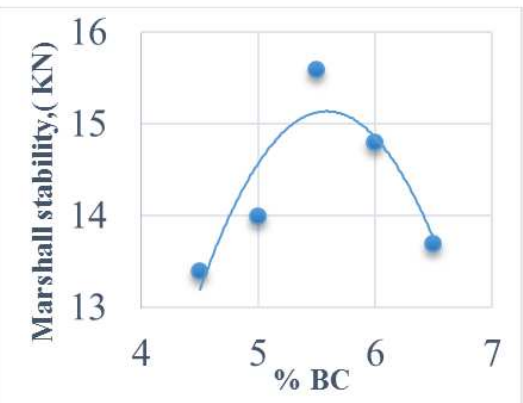

Figure 2. Relationship between Marshall stability and bitumen content.

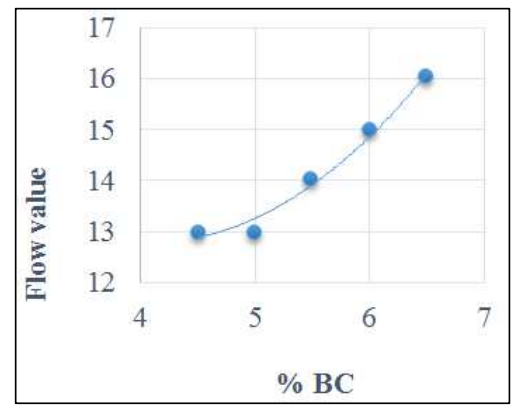

Figure 3. Relationship between flow and bitumen content.

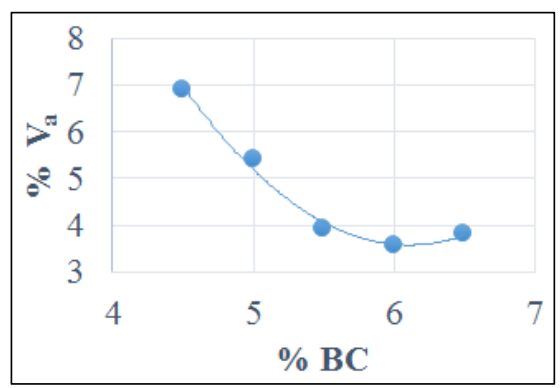

Figure 4. Relationship between voids in total mix and bitumen content.

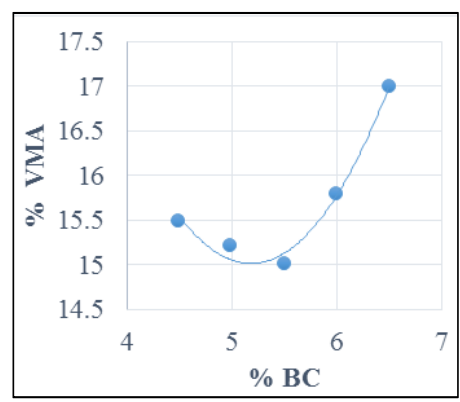

Figure 5. Relationship between void in mineral aggregate and bitumen content.

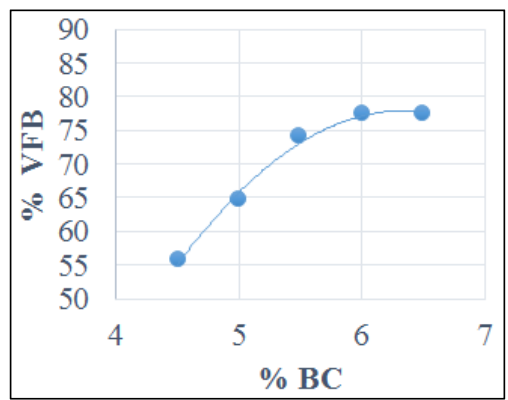

Figure 6. Relationship between voids filled with bitumen and bitumen content.

Optimum bitumen content

The optimum bitumen content is the minimum bitumen content at which maximum density of bituminous paving mix is obtained by averaging the bitumen content for maximum unit weight, bitumen content for maximum stability and bitumen content for $4 \%$ air voids.

$$
\begin{aligned}
\mathrm{OBC}= & \left(\frac{5.63+5.6+5.65}{3}\right) \% \\
& =5.63 \%
\end{aligned}
$$

Table 7. Marshall test results of bituminous mixes with varying RAP percentage.

\begin{tabular}{llllll}
\hline SL NO. & $\mathbf{1}$ & $\mathbf{2}$ & $\mathbf{3}$ & $\mathbf{4}$ & $\mathbf{5}$ \\
\hline \% of RAP & 0 & 10 & 20 & 30 & 40 \\
Unit weight $\left(\mathrm{kg} / \mathrm{m}^{3}\right)$ & 2342 & 2331 & 2320 & 2310 & 2300 \\
Marshall Stability $(\mathrm{KN})$ & 15.25 & 14.95 & 14.4 & 13.22 & 11.68 \\
Flow value, $0.25 \mathrm{~mm}$ & 14 & 15 & 15 & 16 & 17 \\
\% V & 3.9 & 3.87 & 3.7 & 3.55 & 2.95 \\
\% VMA & 15.3 & 15.74 & 16.1 & 16.43 & 16.76 \\
\% VFB & 73.3 & 75.4 & 77 & 78.4 & 82.4 \\
\hline
\end{tabular}

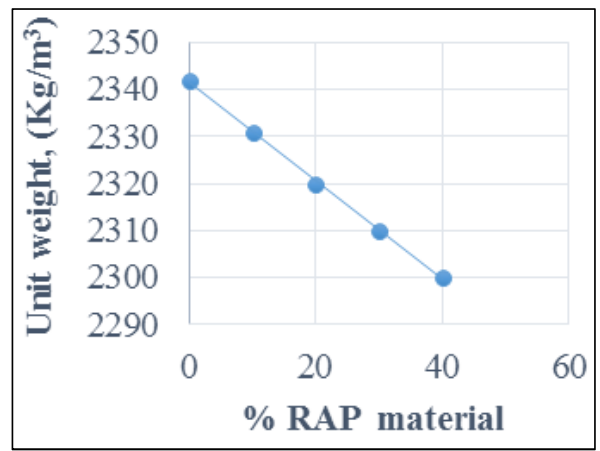

Figure 7. Relationship between unit weight and RAP material. 


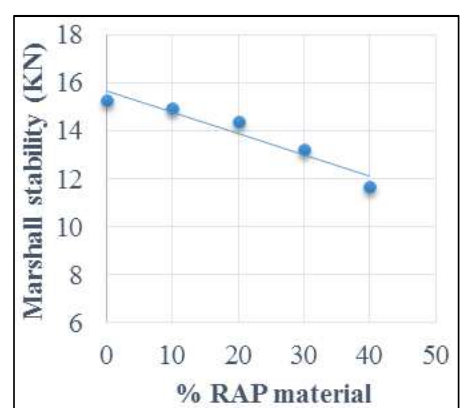

Figure 8. Relationship between Marshall stability and RAP material.

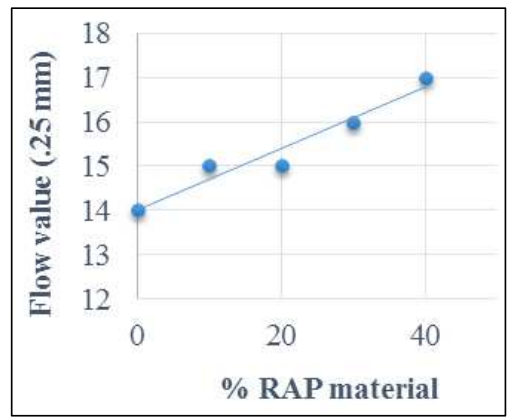

Figure 9. Relationship between flow value and RAP material.

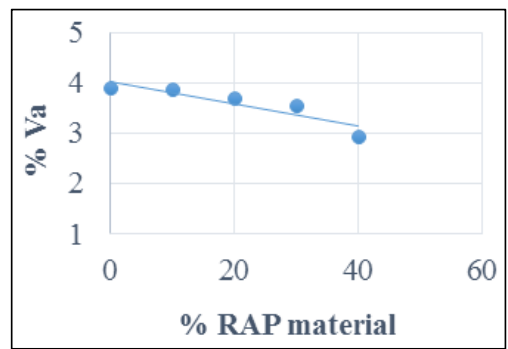

Figure 10. Relationship between voids in total mix and RAP material.

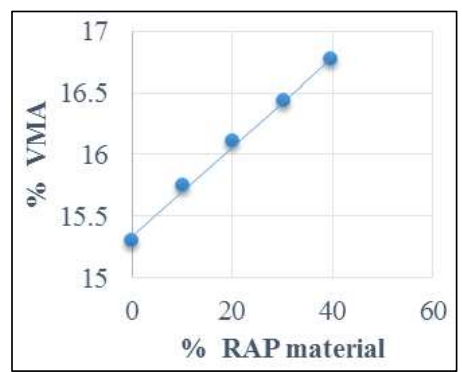

Figure 11. Relationship between void in mineral aggregate and RAP material.

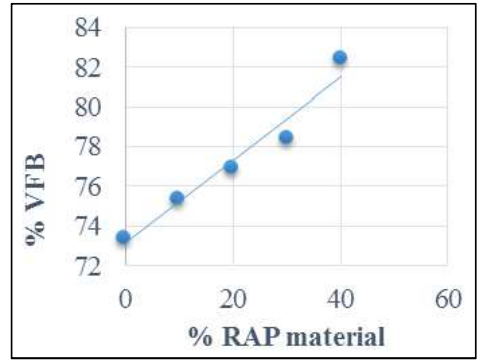

Figure 12. Relationship between void filled with bitumen and RAP material.
From the Table 7, it can be shown that $0 \%, 10 \%$ and $20 \%$ RAP content satisfy Marshall mix design criteria based on medium traffic condition. There is a failure on void filled with bitumen at $30 \%$. So, $0 \%, 10 \%$ and $20 \%$ satisfy traffic requirement. For economical reason 20\% RAP content would be selected.

Table 8. Marshall test results of bituminous mixes taking varying days in water.

\begin{tabular}{llll}
\hline SL NO. & No of Days & Marshall Stability $(\mathbf{K N})$ & Flow value, $\mathbf{0 . 2 5 m m}$ \\
\hline 1 & 0 & 14.4 & 15 \\
2 & 5 & 11.89 & 15 \\
3 & 10 & 9.18 & 16 \\
4 & 15 & 6.63 & 16 \\
5 & 20 & 5.43 & 17 \\
\hline
\end{tabular}

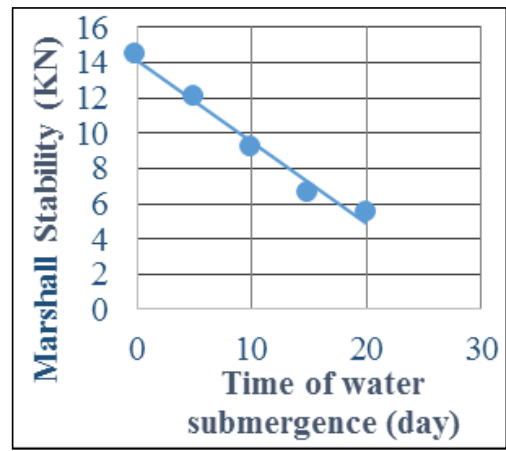

Figure 13. Relationship between Marshall stability and time of water submergence.

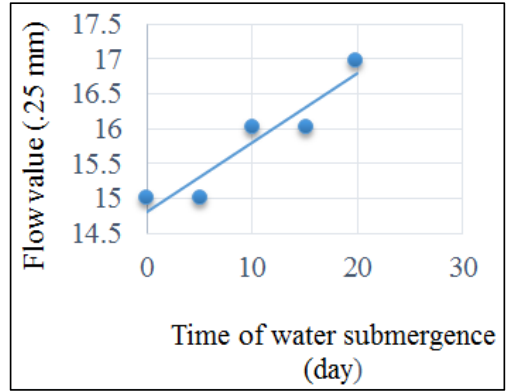

Figure 14. Relationship between flow value and time of water submergence.

From the Table 8 it can be shown that for $20 \%$ RAP content up to 15 days of watering of bituminous mix all values are satisfied medium traffic condition based on Marshall mix design criteria. At 20 days both Marshall stability and flow failure occurs.

\section{Conclusions}

On the basis of experimental results of this study, the following conclusions are drawn.

Optimum bitumen content is $5.63 \%$ for fresh aggregate.

Although stability gradually decreases with the increase of RAP aggregates in the bituminous mixes with fresh stone aggregates, the characteristics of mixes satisfy the Marshall design criteria.

Up to $20 \%$ RAP content, the characteristics of mix satisfy the Marshall mix design criteria. 
Up to 15 days of submergence in water, the characteristics of mix satisfy the Marshall mix design criteria

\section{References}

[1] AASHTO 1983. "American Association of State Highway and Transportation Officials".

[2] Ebrahim, A., El-Maaty, A., and Elmohr, B. I. (2015). "Characterization of Recycled Asphalt Pavement (RAP) for Use in Flexible Pavement", American Journal of Engineering and Applied Sciences, 8 (2), Pp. 233-248.

[3] Hussain, A. and Yanjun, Q. (2012). "Laboratory evaluation of asphalt mixtures containing various percentages of reclaimed asphalt pavement", Asian Journal of Natural \& Applied Sciences, Vol. 1, No. 2, June 2012.

[4] Khanna, (1993). "Highway Engineering", Nem Chand \& Bros, Civil Lines, Roorkee 247 667, INDIA.

[5] Khandal, P. S. (1993). "Waste Materials in Hot Mixes Asphalt and Overview", ASTM International, (Jan 1993).

[6] "Mix Design Method for Asphalt Concrete and other Hot-Mix types" (1997) Manual series No. 2 (MS-2).

[7] Mohamady, A., Elshahat, A., Abd-Elmaksoud, M. F., and Abdallah, H. A. (2014). "Effect of Using Reclaimed Asphalt Pavement on Asphalt Mix Performance", IOSR Journal of Computer Engineering (IOSR-JCE), Volume 16, Issue 6, (Nov-Dec. 2014), Pp 55-67.

[8] Pradyumna, T. A., Mittal, A., and Jain, P. (2013). "Characterization of Reclaimed Asphalt Pavement (RAP) for
Use in Bituminous Road Construction", Procedia -Social and Behavioral Sciences, 104, Pp. 1149-1157.

[9] Pradyumna, T. A., Mittal, A., and Jain, P. (2013). "Characterization of Reclaimed Asphalt Pavement (RAP) for use in bituminous road construction", $2^{\text {nd }}$ Conference of Transportation Research Group of India ( $\left.2^{\text {nd }} C T R G\right), 2013$.

[10] Sunil, S., Mallesh, K., and Chandrasekaraiah, T. (2014). "Experimental investigatiotins on the performance of bituminous mixes with reclaimed asphalt pavement (RAP) materials (case study Tumkur to Chitradurga- $\mathrm{NH}_{4}$ )", International Journal of Research in Engineering and Technology, Volume 3, Issue 06, May 2014.

[11] Spurti, O. T., Kumar, D., and Manjunath. K. R. (2014). "Laboratory investigation on hot mix asphalt using reclaimed asphalt pavement for bituminous concrete mix", International Journal of Research in Engineering and Technology, Volume 03, Issue 06, Jun-2014.

[12] Srikant, Keerthikumar, Pradeep, and Varuna, M. (2014). "Comparative evaluation of warm mix Asphalt containing reclaimed asphalt pavement for DBM II mix", Journal of Civil Engineering Technology and Research", Volume 2, Number 1 (2014), Pp. 561-567.

[13] Tabakovic, A., (2010). "Influence of Recycled Asphalt Pavement on Fatigue Performance of Asphalt Concrete Base Courses', Journal of Materials in Civil Engineering, Vol. 22, No. 6, June 1, 2010.

[14] Udayshankar, C., and Varuna, M. (2013). "Laboratory studies of dense bituminous mixes-II with reclaimed pavement materials", International Journal of Research in Engineering and Technology, Vol. 1, Issue 3, Aug 2013. 